Review

\title{
Metal-Organic Frameworks (MOFs) Based Analytical Techniques for Food Safety Evaluation
}

\author{
Yan Xue ${ }^{1}$, Yao Peng ${ }^{2}$, Zhao Geng ${ }^{3}$, Yitao Wang ${ }^{1}$, Carolina Oi Lam Ung ${ }^{1}$, Hao $\mathrm{Hu}^{1, *}$ \\ ${ }^{1}$ State Key Laboratory of Quality Research in Chinese Medicine, Institute of Chinese Medical Sciences, University of Macau, Macau SAR 999078, China \\ ${ }^{2}$ School of Pharmacy, Hunan University of Chinese Medicine, Changsha, Hunan 410208, China \\ ${ }^{3}$ Sichuan Institute for Food and Drug Control, NMPA Key Laboratory for Quality Evaluation of Traditional Chinese Medicine \\ (Traditional Chinese Patent Medicine), Chengdu, Sichuan 610000, China
}

\section{ARTICLE INFO}

\section{Article History}

Received 19 January 2021

Accepted 08 February 2021

\section{Keywords}

Contaminant

hazardous substance

foodborne

rapid detection

sensor

nanostructure

nanomaterial

pesticide

heavy metal

mycotoxin

\begin{abstract}
As the supply chain of food around the world has become more and more globalized and complicated, food safety issue has attracted considerable concern owing to the widespread pollution of the whole ecosystem and the extent of their impact on the well-being of human beings. Correspondingly, a variety of analysis approaches to detecting and even adsorbing contaminants in food have been extensively explored and investigated. Among them, Metal-Organic Frameworks (MOFs) as potential versatile sensing materials have been utilized in the construction of multitude of sensing platforms with excellent performance to monitor different pollutants of food, including pesticide residues, heavy metals, mycotoxins and so on. Herein, we briefly introduce the progress of the MOFs-based sensing techniques, and then present the typical contributions of representative sensing platforms in detection of pesticides, heavy metals and other contaminants. Finally, we evaluate and discuss the future perspectives and challenges of MOFs in food contaminant analysis.
\end{abstract}

\section{GRAPHICAL ABSTRACT}

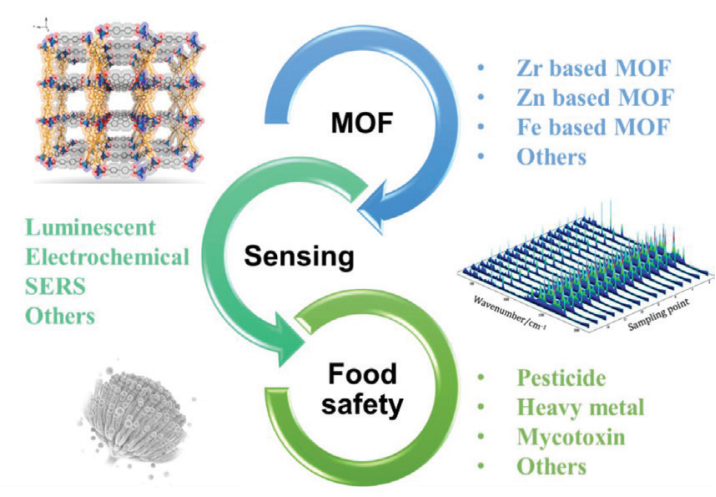

(C) 2021 The Authors. Publishing services by Atlantis Press International B.V. This is an open access article distributed under the CC BY-NC 4.0 license (http://creativecommons.org/licenses/by-nc/4.0/).

\section{INTRODUCTION}

Food, both raw and produced, is an essential part of human life. The imbalanced distribution/supply of food across different regions and people's increasing demand of greater diversity of food have promoted the development of food supply chain dispersed all over the world [1]. In the meanwhile, food with multiple or specific functions have been manufactured and promoted as supplement

"Corresponding author. Email: haohu@um.edu.mo

Peer review under responsibility of the International Association of Dietetic Nutrition and Safety to daily food $[2,3]$. Along with this complicated scenario has food safety issue emerged in recent years.

As summarized by the World Health Organization, more than 200 illnesses that people may suffer in the world are food-borne, which may lead to severe pains to long-term fatal diseases like cancers that could endanger everyone [4]. The significance of food safety has achieved increasing recognition through the policy and regulation making at both national and international levels, owing to its close linkage to the health and well-being of all the individuals [5]. On the one hand, in the current globalized economy, food supply chains inevitably go beyond the regional markets. Contamination of food by various sources at any point during food production, distribution 
and preparation may affect people across national borders [6-8]. On the other hand, the modern agriculture has been revolutionized by the development of biotechnology with large number of biochemical substances applied in the whole food supply chain from land to table. Among them, pesticide residues and heavy metals have attracted great attentions of all the stakeholders with consideration of the risks and hazards that may bring to the consumer. Pesticides are effective in eliminating insects and treating many plant diseases, their residues are notorious for severe damages to the respiratory system, nervous system, reproductive system and the immune system of human bodies and irreversible adverse effects on the bio-system $[9,10]$. Heavy metals as other pollutants have threatened food safety through water system. Due to their low degradability and notorious toxicity, research into sensing platforms of ultralow level heavy metal ions is of great significance [11,12]. Also, Ochratoxin A (OTA) is a highly toxic mycotoxin prevalent in corn, beans, and a series of food related products, which may threaten human life [13,14]. Malachite green is another organic compound that has been illegally used excessively in agriculture as a fungicide $[15,16]$. Therefore, the urgent and upgraded demand of diagnosing, controlling and even removing pesticide residues, heavy metals and other contaminants (e.g. mycotoxin, malachite green, melamine) from fresh food or products has promoted the advancement of relevant technologies to control and ensure food safety.

In recent years, a variety of tailored Metal-Organic Frameworks (MOFs) have been constructed and used as the sensory materials for the establishment of facile and sensitive detection systems $[17,18]$. The versatility of MOFs have been observed in its application in detecting pesticide residues, heavy metals, and other toxic substances with high selectivity and accuracy in food and environmental samples $[8,19]$. Compared with the traditional analytical techniques based on liquid chromatography, gas chromatography or mass spectrometry requiring complex equipment and high-level technical personnel in food analysis, MOF-based sensing techniques might have shown great flexibility, convenience and potential for on-site detection [20-23]. This review will report typical novel MOFs-based sensing techniques for detecting contaminant residues in food and discuss its contributions to food safety by referring to specific application examples in recent 5 -year studies.

\section{VARIOUS TYPES OF MOFS}

Recent studies have reported a variety of MOFs, many of which displayed excellent performance in accurate detection of diverse target pollutants with high selectivity, repeatability and short response time, which cater for the great demand of tailed sensors [19,24-26]. As composites constructed through incorporating specific metal ions/clusters with organic ligands/linkers, MOFs with uniform structures and high porosity possess chemical and physical merits of both inorganic and organic materials. Considering the multitude of the combinations of metal ions and organic ligands, it is important to understand the categories and classification of the MOFs used for food safety evaluation (Tables 1-3). The metal ions commonly seen in the MOFs applied in detection of food contaminants include zirconium, zinc, iron, europium, terbium and so on.

\subsection{Zr-based MOFs}

Zirconium-based MOFs (Zr-MOFs) constitute one of the major types of MOFs. A series of Zr-MOFs have been utilized and performed well in fluorescent sensing, analyte detection, as well as bio-imaging [27]. For instance, a functionalized MOF for determination of cadmium ion was initially fabricated by incorporating

Table 1 List of MOF-based sensing techniques for pesticide detection

\begin{tabular}{|c|c|c|c|c|c|c|c|}
\hline No & Pesticide & MOFs & Ligand & Sensing category & Limit of detection & Sample matrix & References \\
\hline 1 & Parathion-methyl & $\mathrm{Zr}-\mathrm{MOF}$ & $\mathrm{H}_{4} \mathrm{TCPB}$ & Luminescence & $0.438 \mathrm{nM}(0.115 \mu \mathrm{g} / \mathrm{kg})$ & Lettuce and cowpea & [45] \\
\hline 2 & Parathion & {$\left[\mathrm{Cd}(\mathrm{atc})\left(\mathrm{H}_{2} \mathrm{O}\right)_{2}\right]_{n}$} & atc & Electrochemical & $0.1 \mathrm{ng} / \mathrm{mL}$ & Rice & [46] \\
\hline 3 & Chlorpyrifos & $\begin{array}{l}\mathrm{Tb}(\mathrm{tftpa})_{1.5}\left(2,2^{\prime}-\mathrm{bpy}\right) \\
\left(\mathrm{H}_{2} \mathrm{O}\right)\end{array}$ & $\mathrm{H}_{2} \mathrm{tftpa}$ & Fluorescence & $0.14 \mathrm{ppb}$ & ethanol & [47] \\
\hline 4 & Parathion-methyl & $\mathrm{ZnPO}-\mathrm{MOF}$ & $\mathrm{H}_{4} \mathrm{TCPB}$ & Luminescence & $0.456 \mathrm{nM}(0.12 \mathrm{~g} / \mathrm{kg})$ & Irrigation water & [74] \\
\hline 5 & $\begin{array}{l}\text { 2,6-Dichloro-4- } \\
\text { nitroaniline (DCN) }\end{array}$ & {$\left[\mathrm{Zn}_{2}(\mathrm{bpdc})_{2}(\mathrm{BPyTPE})\right]$} & BPyTPE and $\mathrm{H}_{2}$ bpdc & Fluorescence & $0.13 \mathrm{ppm}$ & - & [49] \\
\hline 6 & $\mathrm{DCN}$ & {$\left[\mathrm{Ag}\left(\mathrm{CIP}^{-}\right)\right]$} & HCIP & Fluorescence & $0.17 \mu \mathrm{M}(\sim 105 \mathrm{ppb})$ & - & [50] \\
\hline 7 & $\mathrm{DCN}$ & $\begin{array}{c}{\left[\left[\mathrm{Cd}(\mathrm{tptc})_{0.5}(\mathrm{bpz})\right.\right.} \\
\left.\left.\left(\mathrm{H}_{2} \mathrm{O}\right)\right] \cdot 0.5 \mathrm{H}_{2} \mathrm{O}\right]_{n} \\
{\left[\mathrm{Cd}(\mathrm{tptc})_{0.5}(\mathrm{bpy})\right]}\end{array}$ & $\begin{array}{l}\mathrm{H}_{4} \text { tptc and bpz } \\
\mathrm{H}_{\text {tptc }} \text { and bpy }\end{array}$ & Luminescence & $\begin{array}{l}112 \mathrm{ppb} \\
638 \mathrm{ppb}\end{array}$ & - & [37] \\
\hline 8 & $\begin{array}{l}\text { 2,6-Dichloro- } \\
\text { 4-nitroamine } \\
\text { (2,6-Dich-4-NA) }\end{array}$ & {$\left[\mathrm{Zn}_{3}(\mathrm{DDB})(\mathrm{DPE})\right] \cdot \mathrm{H}_{2} \mathrm{O}$} & $\mathrm{H}_{5} \mathrm{DDB}$ and DPE & Fluorescence & $0.27 \mu \mathrm{M}(\sim 166 \mathrm{ppb})$ & $\begin{array}{l}\text { Carrot, grape and } \\
\text { nectarine extracts }\end{array}$ & [51] \\
\hline 9 & Thiram & Ag@ZIF-8 & Hmim & SERS & $0.1 \mu \mathrm{M}$ & Apple & [52] \\
\hline 10 & Thiram & $\mathrm{Fe}_{3} \mathrm{O}_{4}-\mathrm{Au} @ \mathrm{MIL}-100(\mathrm{Fe})$ & $\mathrm{H}_{3} \mathrm{BTC}$ & SERS & $15 \mathrm{nM}$ & Water & [75] \\
\hline 11 & Paraquat & {$\left[\mathrm{Zn}_{2}(\mathrm{cptpy})(\mathrm{btc})\left(\mathrm{H}_{2} \mathrm{O}\right)\right]_{n}$} & Hcptpy and $\mathrm{H}_{3} \mathrm{BTC}$ & Luminescence & $9.73 \mu \mathrm{M}$ & - & [31] \\
\hline 12 & Atrazine & $\mathrm{Cu}_{2}(\mathrm{BTC})_{2} @ \mathrm{SiO}_{2}$ & $\mathrm{H}_{3} \mathrm{BTC}$ & Electrochemical & $0.01 \mathrm{nM}$ & Water & [36] \\
\hline 13 & Acetamiprid & $\begin{array}{l}\text { AuNP/MOF-199 } \\
\text { AuNP/UiO-66 } \\
\text { AuNP/UiO-67 }\end{array}$ & $\begin{array}{l}\mathrm{H}_{3}^{3} \mathrm{BTC} \\
\text { PTA, } \mathrm{H}_{2} \mathrm{BDC} \\
\mathrm{H}_{3} \text { bpdc }\end{array}$ & SERS & $\begin{array}{l}0.02 \mu \mathrm{M} \\
0.009 \mu \mathrm{M} \\
0.02 \mu \mathrm{M}\end{array}$ & - & [76] \\
\hline
\end{tabular}

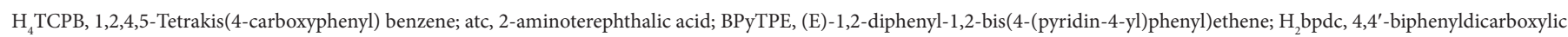
acid; $\mathrm{H}_{5} \mathrm{DDB}, 3,5$-di(2',4'-dicarboxylphenyl)benzoic acid; DPE, 1,2-di(4-pyridyl)ethylene; HCIP, 4-(4-carboxylphenyl)-2,6-di(4-imidazol-1-yl)phenyl)pyridine); $\mathrm{H}_{4}$ tptc, $p$-terphenyl2,2" $5^{\prime \prime}, 5^{\prime \prime \prime}$-tetracarboxylate acid; bpz, 2-(1H-pyrazol-3-yl)pyridine, bpy, 2,2'-bipyridine; $\mathrm{H}_{3}$ BTC, benzene-1,3,5-tricarboxylic acid; PTA, $\mathrm{H}_{2} \mathrm{BDC}$, terephthalic acid; $\mathrm{H}_{2}$ tftpa, 
Table 2 List of MOF-based sensing techniques for heavy metal detection

\begin{tabular}{|c|c|c|c|c|c|c|c|}
\hline No & $\begin{array}{l}\text { Heavy } \\
\text { metal }\end{array}$ & MOFs & Ligand & Sensing category & Limit of detection & Sample & References \\
\hline 1 & $\mathrm{Hg}^{2+}$ & $\begin{array}{l}{\left[\mathrm{Zn}(\mathrm{OBA})-(\mathrm{DPT})_{0.5}\right] \cdot \mathrm{DMF}} \\
(\mathrm{TMU}-34(-2 \mathrm{H}))\end{array}$ & $\mathrm{H}_{2} \mathrm{OBA}$ and DPT & Luminescent & $\begin{array}{l}1.8 \mu \mathrm{M} \text { in water } \\
6.9 \mu \mathrm{M} \text { in acetonitrile }\end{array}$ & Water & {$[55]$} \\
\hline 2 & $\begin{array}{l}\mathrm{Hg}^{2+} \\
\mathrm{Pb}^{2+}\end{array}$ & $\begin{array}{l}\mathrm{Zn}_{2}\left(\mathrm{dbtdcO}_{2}\right)_{2}(\mathrm{tppe}) \\
(\mathrm{LMOF}-263)\end{array}$ & $\begin{array}{l}\mathrm{H}_{2} \mathrm{dbtdcO}_{2} \text { and } \\
\text { tppe }\end{array}$ & Luminescent & $\begin{array}{l}3.3 \mathrm{ppb} \\
4.9 \mathrm{ppb}\end{array}$ & - & {$[56]$} \\
\hline 3 & $\mathrm{Hg}^{2+}$ & ssDNA labeled UiO-66- $\mathrm{NH}_{2}$ & $\mathrm{H}_{2} \mathrm{BDC}-\mathrm{NH}_{2}$ & Luminescent & $17.6 \mathrm{nM}$ & - & {$[57]$} \\
\hline 4 & $\mathrm{Hg}^{2+}$ & $\mathrm{Tb}$ (TATAB) $\cdot(\mathrm{DMF})_{4}\left(\mathrm{H}_{2} \mathrm{O}\right)(\mathrm{MeOH})_{05}$ & $\mathrm{H}_{3}^{2}$ TATAB & Luminescent & $4.4 \mathrm{nM}$ & Natural water & [58] \\
\hline 5 & $\mathrm{Fe}^{3+}$ & $\mathrm{UO}_{2}\left(\mathrm{C}_{8} \mathrm{H}_{3} \mathrm{O}_{6} \mathrm{~N}\right) \cdot \mathrm{DMF}$ & $\mathrm{H}_{2} \mathrm{~L}$ & Luminescent & $6.3 \mathrm{ppb}$ & - & {$[60]$} \\
\hline 6 & $\begin{array}{l}\mathrm{Fe}^{3+} \\
\mathrm{Cr}^{3+}\end{array}$ & $\begin{array}{l}{\left[\left[\mathrm{Eu}_{2}(\mathrm{pdba})_{3}\left(\mathrm{H}_{2} \mathrm{O}\right)_{3}\right] \cdot 2 \mathrm{H}_{2} \mathrm{O}\right]_{n}} \\
{\left[\left[\mathrm{Eu}_{3}(\mathrm{pdba})_{4}\left(\mathrm{H}_{2} \mathrm{O}\right)_{4}\right] \cdot 5 \mathrm{H}_{2} \mathrm{O}\right]_{n}}\end{array}$ & $\mathrm{H}_{2}^{2} \mathrm{pdba}$ & Luminescent & $1.0 \mu \mathrm{M}$ & - & {$[34]$} \\
\hline 7 & $\mathrm{Fe}^{3+}$ & $\begin{array}{l}{\left[\mathrm{Zr}_{6} \mathrm{O}_{4}(\mathrm{OH})_{8}\left(\mathrm{H}_{2} \mathrm{O}\right)_{4}\left(\mathrm{~L}^{1}\right)_{2}\right](\text { BUT-14) }} \\
{\left[\mathrm{Zr}_{6} \mathrm{O}_{4}(\mathrm{OH})_{8}\left(\mathrm{H}_{2} \mathrm{O}\right)_{4}\left(\mathrm{~L}^{2}\right)_{2}\right](\text { BUT-15) }}\end{array}$ & $\begin{array}{l}\mathrm{H}_{4} \mathrm{~L}^{1} \\
\mathrm{H}_{4} \mathrm{~L}^{2}\end{array}$ & Luminescent & $\begin{array}{l}3.79 \mu \mathrm{M}(212 \mathrm{ppb}) \\
0.286 \mu \mathrm{M}(16 \mathrm{ppb})\end{array}$ & - & {$[61]$} \\
\hline 8 & $\mathrm{Fe}^{3+}$ & $\begin{array}{l}{\left[\mathrm{Zr}_{6} \mathrm{O}_{4}(\mathrm{OH})_{4}\left(\mathrm{C}_{8} \mathrm{H}_{2} \mathrm{O}_{4} \mathrm{~S}_{2}\right)_{6}\right] \cdot \mathrm{DMF} \cdot 18 \mathrm{H}_{2} \mathrm{O}} \\
{\left[\mathrm{Zr}_{6} \mathrm{O}_{4}(\mathrm{OH})_{4}\left(\mathrm{C}_{10} \mathrm{H}_{6} \mathrm{O}_{4} \mathrm{~S}_{2}\right)_{6}\right] \cdot 4.8 \mathrm{DMF} \cdot 10 \mathrm{H}_{2} \mathrm{O}} \\
{\left[\mathrm{Zr}_{6} \mathrm{O}_{4}(\mathrm{OH})_{4}\left(\mathrm{C}_{15} \mathrm{H}_{8} \mathrm{O}_{4} \mathrm{~S}_{2}\right)_{6}\right] \cdot 4 \mathrm{DMF} \cdot 21 \mathrm{H}_{2} \mathrm{O}} \\
{\left[\mathrm{Zr}_{6} \mathrm{O}_{4}(\mathrm{OH})_{4}\left(\mathrm{C}_{20} \mathrm{H}_{10} \mathrm{O}_{4} \mathrm{~S}_{2}\right)_{6}\right] \cdot 2.5 \mathrm{DMF} \cdot 11 \mathrm{H}_{2} \mathrm{O}}\end{array}$ & $\begin{array}{l}\mathrm{H}_{2}^{4} \text { TDC } \\
\mathrm{H}_{2} \text { DMTDC } \\
\mathrm{H}_{2} \text { MPTDC } \\
\mathrm{H}_{2} \text { DPTDC }\end{array}$ & Luminescent & $\begin{array}{l}1.26 \mu \mathrm{M} \\
0.86 \mu \mathrm{M} \\
0.93 \mu \mathrm{M} \\
0.34 \mu \mathrm{M}\end{array}$ & - & {$[77]$} \\
\hline 9 & $\begin{array}{l}\mathrm{CrO}_{4}^{2-} \text { and } \\
\mathrm{HCrO}_{4}^{-}\end{array}$ & $\begin{array}{l}{\left[\mathrm{Eu}_{7}(\mathrm{mtb})_{5}\left(\mathrm{H}_{2} \mathrm{O}\right)_{16}\right] \cdot \mathrm{NO}_{3} \cdot 8 \mathrm{DMA} \cdot 18 \mathrm{H}_{2} \mathrm{O}} \\
\text { Eu-MOF }\end{array}$ & $\mathrm{H}_{4}^{2} \mathrm{mtb}$ & Luminescent & $\begin{array}{l}0.56 \mathrm{ppb} \\
2.88 \mathrm{ppb} \\
1.75 \mathrm{ppb}\end{array}$ & $\begin{array}{l}\text { Deionized water } \\
\text { lake water } \\
\text { seawater }\end{array}$ & {$[63]$} \\
\hline 10 & $\mathrm{Cr}_{2} \mathrm{O}_{7}^{2-}$ & {$\left[\mathrm{Cd}(\mathrm{TIPA})_{2}\left(\mathrm{ClO}^{4-}\right)_{2}\right] \cdot(\mathrm{DMF}) 3\left(\mathrm{H}_{2} \mathrm{O}\right)$} & TIPA & Luminescent & $8 \mathrm{ppb}$ & - & [64] \\
\hline 11 & $\mathrm{Cd}^{2+}$ & UiO-66- $\mathrm{NH}_{2} @ \mathrm{PANI}$ & $\mathrm{H}_{2} \mathrm{BDC}-\mathrm{NH}_{2}$ & Electrochemical & $0.3 \mu \mathrm{g} / \mathrm{L}$ & $\begin{array}{l}\text { Lake water, tap } \\
\text { water, saliva } \\
\text { and urine }\end{array}$ & [29] \\
\hline 12 & $\mathrm{Cd}^{2+}$ & $\mathrm{Eu}^{3+} @ \mathrm{UiO}-66(\mathrm{Zr})-(\mathrm{COOH})_{2}$ & $\mathrm{H}_{4}$ btec & Luminescent & $0.06 \mu \mathrm{M}$ & $\begin{array}{l}\text { Tap water and } \\
\text { lake water }\end{array}$ & [28] \\
\hline 13 & $\mathrm{~Pb}^{2+}$ & $(\mathrm{Fe}-\mathrm{P})_{n}-\mathrm{MOF}-\mathrm{Au}-\mathrm{GR}$ & Tmpp & Electrochemical & $0.02 \mathrm{nM}$ & $\begin{array}{l}\text { Water, fruit } \\
\text { juice and solid } \\
\text { samples }\end{array}$ & {$[78]$} \\
\hline 14 & $\mathrm{Cu}^{2+}$ & BPEI-CQDs/ZIF-8 composite & Hmim & Luminescent & $80 \mathrm{pM}$ & River water & {$[30]$} \\
\hline 15 & $\mathrm{Bi}^{3+}$ & $\begin{array}{l}{\left[\mathrm{Al}_{8}(\mathrm{OH})_{4}\left(\mathrm{OCH}_{3}\right)_{8}\left(\mathrm{BDC}(\mathrm{OH})_{2}\right)_{6}\right] \cdot x \mathrm{H}_{2} \mathrm{O}} \\
\quad\left(\mathrm{CAU}-1-(\mathrm{OH})_{2}\right)\end{array}$ & $\mathrm{H}_{2} \mathrm{BDC}(\mathrm{OH})_{2}$ & Luminescent & $2.16 \mu \mathrm{M}$ & Water & [79] \\
\hline 16 & $\mathrm{Co}^{2+}$ & {$\left[\left[\mathrm{Cd}_{1.5}(\mathrm{TPO})(\text { bipy })_{1.5}\right] \cdot 3 \mathrm{H}_{2} \mathrm{O}\right]_{2 n}$} & $\mathrm{H}_{3} \mathrm{TPO}$ & Luminescent & $0.31 \mu \mathrm{M}$ & - & {$[80]$} \\
\hline 17 & $\mathrm{UO}_{2}^{2+}$ & {$\left[\mathrm{Tb}(\mathrm{BPDC})_{2}\right] \cdot\left(\mathrm{CH}_{3}\right)_{2} \mathrm{NH}_{2}(\mathrm{DUT}-101)$} & $\mathrm{H}_{2} \mathrm{bpdc}$ & Luminescent & $8.34 \mu \mathrm{g} / \mathrm{L}$ & Water & [35] \\
\hline
\end{tabular}

$\mathrm{H}_{2} \mathrm{OBA}, 4,4^{\prime}$-oxybis(benzoic acid); DPT, 3,6-di(pyridin-4-yl)-1,2,4,5-tetrazine; $\mathrm{H}_{3}$ TATAB, 4,4',4"-s-triazine-1,3,5-triyltri- $p$-aminobenzoic acid; $\mathrm{H}_{2}$ dbtdco ${ }_{2}$, dibenzo[b,d] thiophene3,7-dicarboxylic acid-5,5-dioxide; Tppe, 1,1,2,2-tetrakis(4-(pyridin-4-yl)phenyl)ethane; $\mathrm{H}_{2}$ BDC-NH ${ }_{2}$, 2-aminoterephthalic acid; $\mathrm{H}_{4} \mathrm{mtb}$, 4-[tris(4-carboxyphenyl)methyl]benzoic acid; PANI, polyaniline; $\mathrm{H}_{4}$ btec, 1,2,4,5-benzenetetracarboxylic acid; Tmpp, (5,10,15,20-tetrakis(4-methoxyphenyl)porphyrinate); $\mathrm{H}_{2} \mathrm{~L}$, $9 H$-carbazole2,7-dicarboxylic acid; $\mathrm{H}_{2}$ pdba, 4'-(1H-pyrazol-3-yl)-[1,1'-biphenyl]-3,5-dicarboxylic acid; $\mathrm{H}_{2}$ TDC, thieno[2,3-b]thiophene-2,5-dicarboxylic acid; $\mathrm{H}_{2} \mathrm{DMTDC}$, 3,4-dimethylthieno[2,3-b] thiophene-2,5-dicarboxylicacid; $\mathrm{H}_{2}$ MPTDC, 3-methyl-4-phenylthieno[2,3-b] thiophene-2,5-dicarboxylic acid; $\mathrm{H}_{2}$ DPTDC, 3,4-diphenylthieno[2,3-b]thiophene-2,5-dicarboxylic acid; $\mathrm{H}_{4} \mathrm{~L}^{1}, 5^{\prime}, 5^{\prime \prime \prime}$-bis (4-carboxyphenyl)-[1,1':3',1": $4^{\prime \prime}, 1^{\prime \prime \prime}: 3^{\prime \prime \prime}, 1^{\prime \prime \prime}$-quinquephenyl]-4,4"'-dicarboxylic acid; $\mathrm{H}_{4} \mathrm{~L}^{2}, 4,4^{\prime}, 4^{\prime \prime}, 4^{\prime \prime \prime}$-(4,4'-(1,4-phenylene)bis(pyridine-6,4,2-triyl))-tetrabenzoic acid; TIPA, tri(4-imidazolylphenyl) amine; $\mathrm{H}_{2} \mathrm{BDC}(\mathrm{OH})_{2}$, 2,5-dihydroxyterephthalic acid; $\mathrm{H}_{3} \mathrm{TPO}$, tris(paracarboxylphenyl) phosphine oxide.

Table 3 List of MOF-based sensing techniques for other contaminants detection

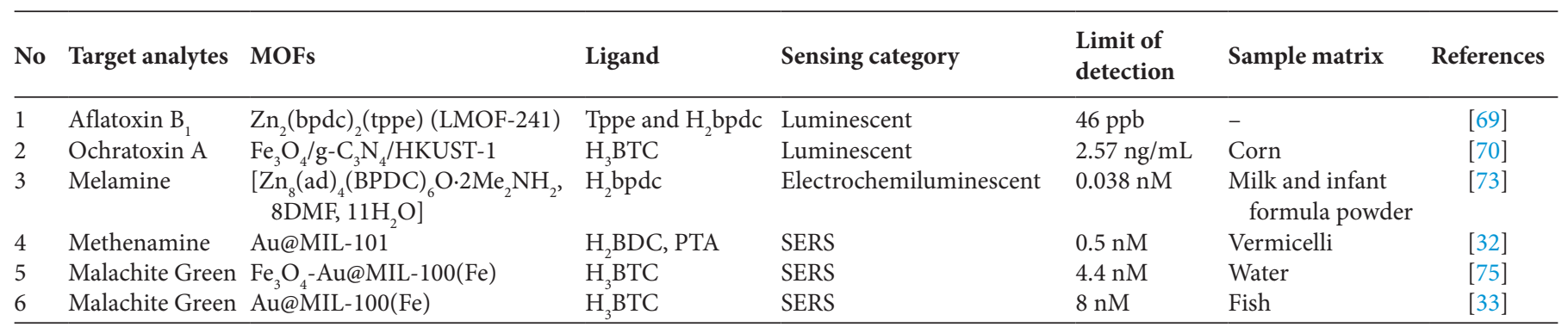

$\mathrm{Eu}^{3+}$ into the UiO-66(Zr)-(COOH $)_{2}$ [28]. This MOF demonstrated excellent fluorescence response toward various concentrations of $\mathrm{Cd}^{2+}$ with high fluorescence intensity in aqueous solutions. The Limit of Detection (LOD) of this MOF was found to be as low as $0.06 \mu \mathrm{M}$. In the preparation of conductive electrochemical sensor, another Zr-based MOF UiO-66- $\mathrm{NH}_{2}$ was coated by the polymer Polyaniline (PANI) with high conductivity [29]. The modified electrode UiO-66- $\mathrm{NH}_{2} @$ PANI with a core/shell structure showed high sensitivity and selectivity in the detection of trace cadmium ions with LOD at $0.3 \mu \mathrm{g} / \mathrm{L}$. 


\subsection{Zn-based MOFs}

Another major type of novel MOFs is Zinc-based MOFs (Zn-MOFs). Among them, Zeolitic imidazolate framework (ZIF-8) MOFs are very common in the synthesis of different sensing electrodes. These zeolitic imidazole-based MOFs possess the advantages of MOFs (i.e., high porosity and surface area, transition metal centers, and tailored linkers) with high stability, chemical robustness, and framework diversity. An as-prepared fluorescent (FL)-functionalized MOFs [i.e., branched poly-(ethylenimine)-capped carbon quantum dots (BPEI-CQDs)/ZIF-8] was fabricated by encapsulating a highly fluorescent amine-capped carbon-based quantum dots into ZIF-8 MOFs [30]. These composites have been tested to be excellent sensors of Copper ions with their outstanding sensitivity and selectivity, with a very low detection limit of $80 \mathrm{pM}$. Another good example is a 3D-structured MOF obtained by assembling $\mathrm{d}^{10}$-electronic-configuration $\mathrm{Zn}^{2+}$ ions with two trigonal ligands an elongated terpyridine-carboxylic acid ligand, 4-(4-carboxyphenyl)$2,2^{\prime}: 4^{\prime}, 4^{\prime \prime}$-terpyridine (Hcptpy), and an auxiliary ligand, 1,3,5benzenetricarboxylic acid ( $\mathrm{H}_{3} \mathrm{BTC}$ ) [31]. This MOF has been found to be highly selective and sensitive in the detection of paraquat in aqueous solution.

\subsection{Fe-based MOFs}

Iron-based MOFs (Fe-based MOFs) have been utilized for the establishment of MOF-based Surface-enhanced Raman scattering (SERS) assays, and applied in the analysis of different food contaminants, especially the small molecular environmental pollutants. In recent studies, the core-shell structures with Au Nanoparticle (AuNP) core and Fe-based MOFs [e.g. MIL-100 (Fe), MIL-101 $(\mathrm{Fe})]$ have been established in the SERS sensing platforms for the detection of residual methenamine [32] and malachite green [33].

\subsection{Other Metal-based MOFs}

There are also other metal ions utilized in the construction of functional MOFs. Lanthanide-based MOFs (i.e. $\mathrm{Eu}^{3+}$ and $\mathrm{Tb}^{3+}$ ) demonstrated their great merits as sensing materials owing to the electron transitions of Ln (III) ions. Two Europium-based MOFs (Eu-MOFs) were reported to have fascinating selectivity toward $\mathrm{Fe}^{3+}$ and $\mathrm{Cr}^{3+}$ with their excellent luminescence performance and high stability in water [34]. Another terbium MOF showed high selectivity and sensitivity toward mercury ions in aqueous solution [35]. Furthermore, calcium-, copper- and other metal-based MOF were successfully developed for the detection of pesticide, heavy metal, mycotoxin and related contaminants in real samples [36-38].

\section{APPLICATIONS IN FOOD CONTAMINANT ANALYSIS}

\subsection{Pesticide Residues}

\subsubsection{Detection of OPPs}

Organophosphorus Pesticides (OPPs) are the major type of pesticides used worldwide with their efficiency in improving the yield of the modern agriculture [39]. Consequently, the widespread or even excessive use has led to pesticide poisoning accidents and accumulated residues in soil, ground water and food that are essential to human beings [40]. Therefore, there is an urgent need to develop facile and reliable analytical methods of detecting OPP residues for the food safety and human health [41-44]. To detect trace amount of OPPs in real food and environmental samples, a facile and low-cost Zr-MOF was established [45]. This 3D rod-like luminescence probe with strong hydro-stability, photostability and thermal stability in aqueous solutions was synthesized through the solvothermal method by using $\mathrm{Zr}$ (IV) and 1,2,4,5-tetrakis (4-carboxyphenyl) benzene $\left(\mathrm{H}_{4} \mathrm{TCPB}\right)$. This $\mathrm{Zr}-\mathrm{MOF}$ presents excellent selectivity toward parathion-methyl due to its intrinsic advantage of exceptionally strong adsorption ability. Its luminescence quenching response toward parathion-methyl was plausibly owing to the photoexcited transfer. In the test of real food samples (lettuce and cowpea), this zirconium-luminescent MOF (Zr-LMOF) performed high selectivity toward parathion-methyl with a low LOD of $0.438 \mathrm{nM}$ (Figure 1A). In another pesticide sensing platform established based on a nano-MOF mainly for detection of parathion, 2-Aminobenzylamine (2-ABA) modified on indium tin oxide was selected as the solid ligand for the synthesis of this MOF formulated as $\left[\mathrm{Cd}(\text { atc })\left(\mathrm{H}_{2} \mathrm{O}\right)_{2}\right]_{n}$. This MOF showed excellent performance in detecting parathion in a rice sample with a LOD as low as $0.1 \mathrm{ng} / \mathrm{mL}$ [46]. Lanthanide-based MOF (Ln-MOF) probe were prepared by using tetrafluoroterephthalic acid $\left(\mathrm{H}_{2} \mathrm{tftpa}\right)$ as the organic ligand for the detection of chlorpyrifos and Di- $n$-butylphthalate(DBP) for the first time. Thisluminescence sensor displayed high sensitivity toward chlorpyrifos in ethanol and DBP in seawater with the detection limits of 0.14 and $2.07 \mathrm{ppb}$, respectively [47].

\subsubsection{Detection of 2,6-dichloro-4- nitroaniline}

2,6-Dichloro-4-Nitroaniline (DCN) as a typical organochlorine pesticide with extremely high toxicity. Its poor degradability leads to long-term pollution of the environmental surroundings and food produced consequently [48]. Although there have been many common analytical methods used in the DCN detection, most of them have rigid requirements in finance and manpower. Therefore, to detect low concentration of DCN in agricultural products with facial and low-cost methods, a novel and reversible sensing strategy was established with a new synthesized luminescent MOF in the pillar-layer-interpenetration structure $\left[\mathrm{Zn}_{2}(\mathrm{bpdc})_{2}(\mathrm{BPyTPE})\right]$ (Figure 1B). This composite with satisfactory aggregation-induced emission characteristics exhibits exceptionally high quantum yield of $99 \%$. This MOF has been proved to be remarkably selective toward nitroaniline and consequently sensitive in detecting trace residues of DCN with a linear range of 0.95-16.92 ppm and a low detection limit of $0.13 \mathrm{ppm}$ [49]. Another luminescent sensor for detecting DCN was an Ag-based MOF synthesized through the solvothermal method by utilizing the multifunctional solid ligand 4-(4-carboxylphenyl)-2,6-di(4-imidazol-1-yl)phenyl)pyridine). The MOF formulated as $\left[\mathrm{Ag}\left(\mathrm{CIP}^{-}\right)\right]$demonstrated high selectivity and sensitivity toward DCN with a low LOD $(0.17 \mu \mathrm{M}$, $\sim 105 \mathrm{ppb}$ ) based on its strong luminescence quenching effect [50]. Using $p$-terphenyl-2,2",5",5"'-tetracarboxylate acid as the ligand, 
A

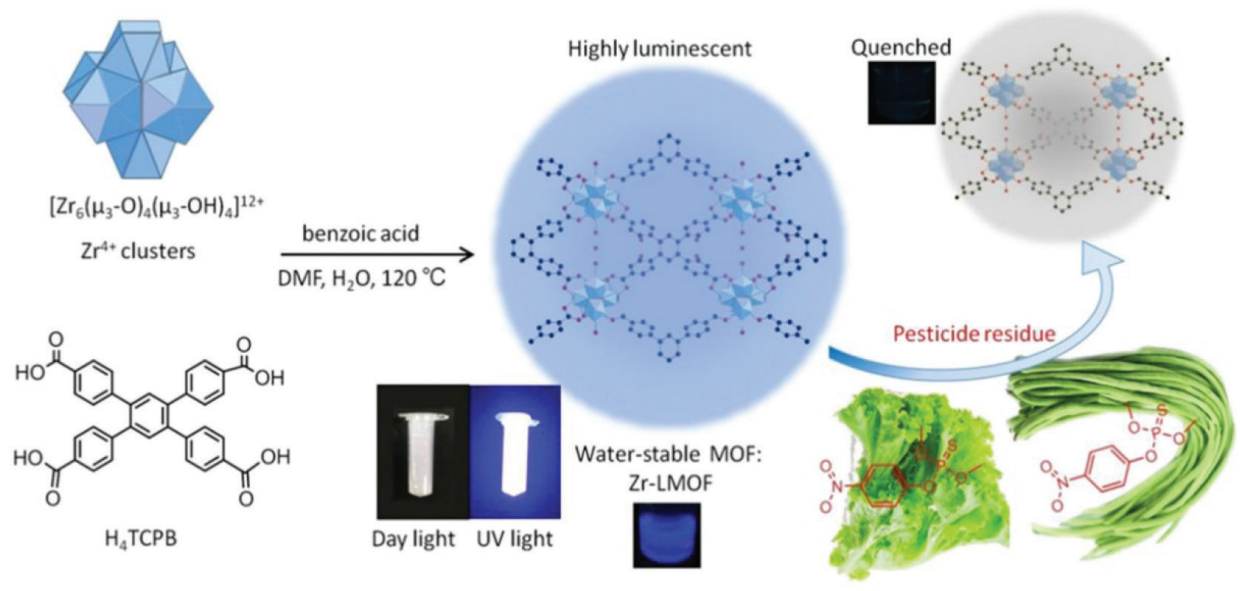

B

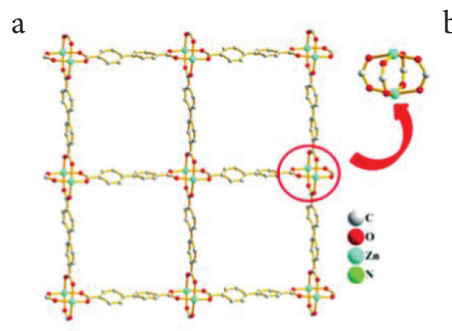

$\mathrm{d}$

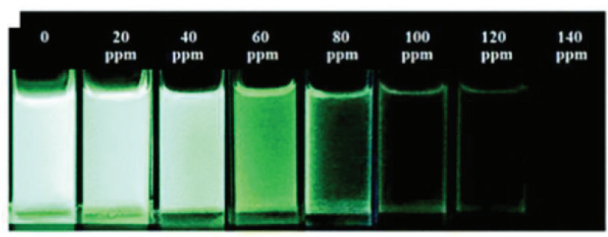

b
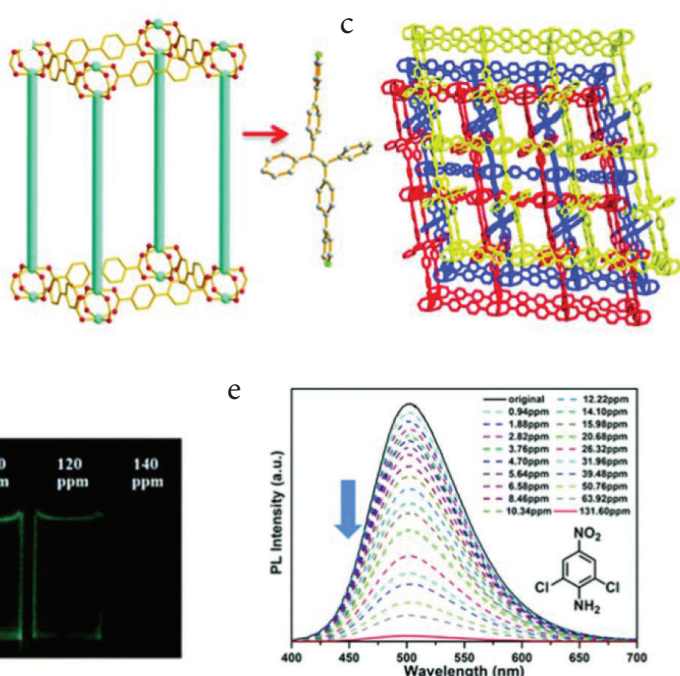

Figure 1 (A) Schematic diagram for synthesis of water-Stable Zr-LMOF and its application for organophosphorus pesticide sensing. (B) Topological representation of rhombic $4^{4}$ two-dimensional paddle-wheel layer with an indicated structure of paddle-wheel secondary building unit [ $\left.\mathrm{Zn}_{2}(\mathrm{COO})_{4}\right]$ (a); Single net of $\left[\mathrm{Zn}_{2}(\mathrm{bpdc})_{2}(\mathrm{BPyTPE})\right]$ viewed along the $a$-axis (b); The overall crystal structure demonstrating the threefold interpenetration and $1 \mathrm{D}$ pore running along the $b$-axis (c); Fluorescence photos of $\left[\mathrm{Zn}_{2}(\mathrm{bpdc})_{2}(\mathrm{BPyTPE})\right]$ in suspensions with gradually increased 2,6-Dichloro-4-nitroaniline $(\mathrm{DCN})(\mathrm{d})$; Fluorescence titration of $\left[\mathrm{Zn}_{2}(\mathrm{bpdc})_{2}(\mathrm{BPyTPE})\right]$ in a dichloromethane suspension of DCN with different concentrations $\left(\lambda_{\mathrm{ex}}=365 \mathrm{~nm}\right)$.

Fan et al. [37] reported to develop the first cadmium (II)-based MOFs for detection of DCN and Cr (VI) anions simultaneously. In particular, both of the crystalline compounds, i.e. [ $\left[\mathrm{Cd}(\mathrm{tptc})_{0.5}\right.$ $\left.\left.(\mathrm{bpz})\left(\mathrm{H}_{2} \mathrm{O}\right)\right] \cdot 0.5 \mathrm{H}_{2} \mathrm{O}\right]_{n}(1)$, and $\left[\mathrm{Cd}(\mathrm{tptc})_{0.5}(\mathrm{bpy})\right]_{n}$ (2), could sensitively identify DCN with LOD being 112 and 638 ppb respectively. As a multifunctional luminescence probe, this MOF could detect $\mathrm{CrO}_{4}^{2-}, \mathrm{Cr}_{2} \mathrm{O}_{7}^{2-}$ and nitrofurantoin simultaneously. Further, a 3D-structured $\mathrm{Zn}$-based MOF with excellent sensing performance was reported toward 2,6-dichloro-4-nitroamine, Cr (III/ $\mathrm{VI}), \mathrm{Fe}$ (III) and Mn (VII) in aqueous solution [51]. There are six nuclear clusters in this crystalline composite, $\left[\mathrm{Zn}_{3}(\mathrm{DDB})\right.$ (DPE) $] \cdot \mathrm{H}_{2} \mathrm{O}(1)$, which is bridged by DPE and $\mathrm{H}_{5} \mathrm{DDB}$ ligands. The nature of this structure results in predominant stability of this composite in water and acid. Its high quenching efficiency was possibly attributed to the competition for adsorption between MOF and analyte, electron molecular internal energy transfer, and photoexcited transfer as well. As the first multi-responsive luminescence-based sensor, this MOF material qualifies to be an ideal sensory material in detection of DCN in real carrots, grapes and nectarine extracts samples (LOD, $0.27 \mu \mathrm{M}$ ).

\subsubsection{Detection of other pesticides}

Recently, necklace-like Ag@ZIF-8 core/shell heterostructure nanowires were established for the pesticide detection, the synthesis process of which only requires two major steps [52]. This heterostructure substrate exhibited exceptionally high SERS enrichment factor up to $4.2 \times 10^{7}$ for crystal violet molecules, which could remain stable for almost 2 months. Moreover, this substrate displays high sensitivity toward thiram with difference concentrations in trace amount on apple peels (LOD, $0.1 \mu \mathrm{M}$ ). For nitrogen heterocycles detection, a 3D luminescent MOF with the formula $\left[\mathrm{Zn}_{2} \text { (cptpy) }(\mathrm{btc})\left(\mathrm{H}_{2} \mathrm{O}\right)\right]_{n}$ was synthesized by incorporating two ligands Hcptpy and $\mathrm{H}_{3} \mathrm{BTC}$ with $\mathrm{Zn}$ (II) for detecting Paraquat in aqueous solutions (Figure 2) [31]. This compound with $(3,3,4,4)$-connected topology showed strong stability in air and water. An excellent luminescence quenching response was observed with a very low LOD value at $9.73 \mu \mathrm{M}$, which was probably owing to interactions and energy transfer between the composite and the analytes. And the good reusability of this luminescence probe qualifies it to be a desirable candidate as a fluorescent chemical sensor. 

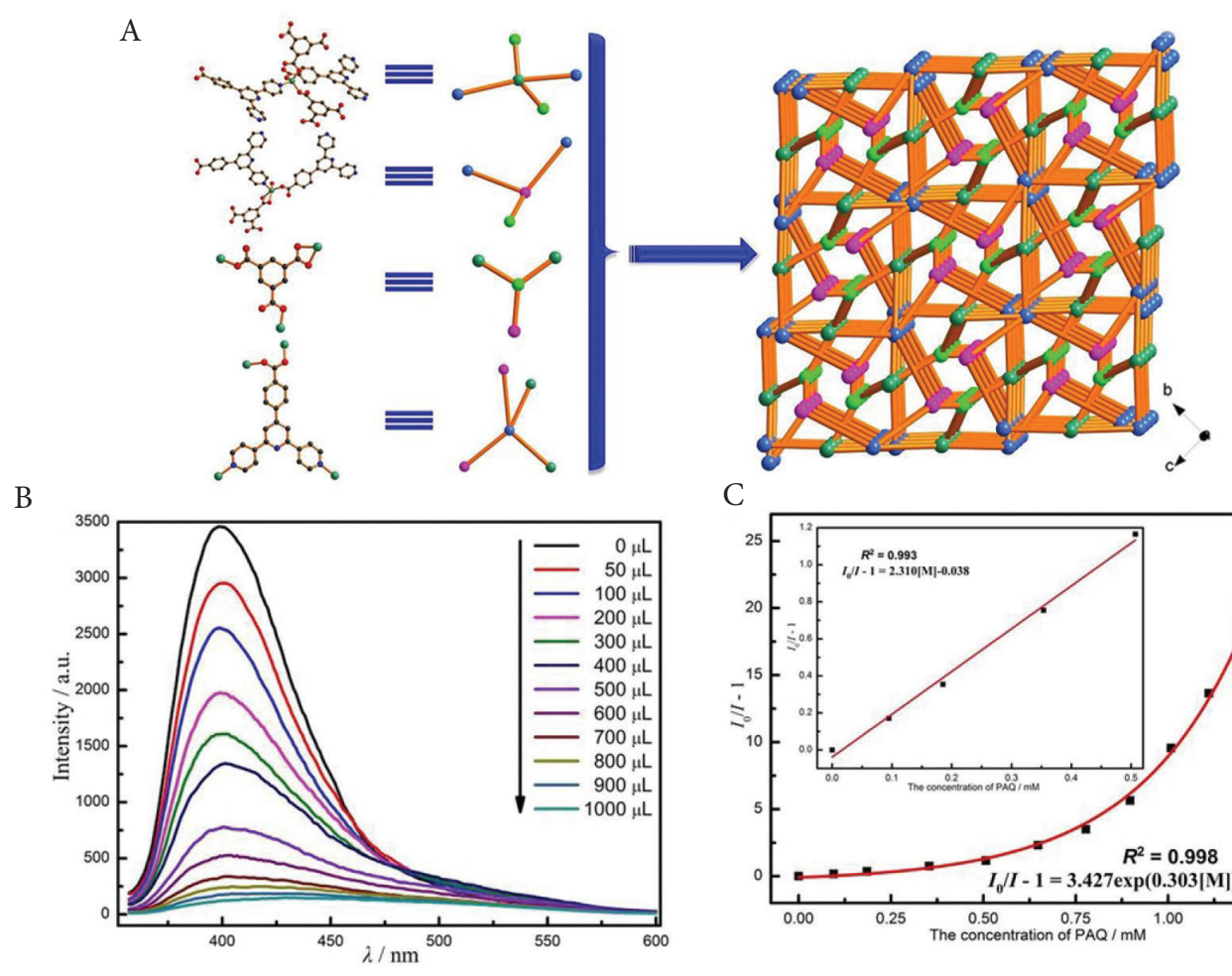

C

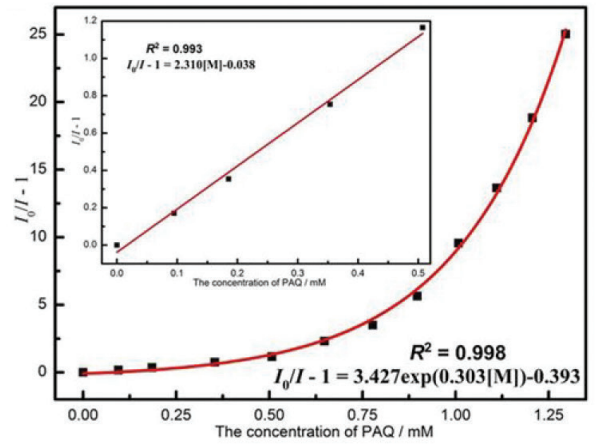

Figure 2 (A) Schematic representation of the $(3,3,4,4)$-connected topology in $\left[\mathrm{Zn}_{2} \text { (cptpy)(btc) }\left(\mathrm{H}_{2} \mathrm{O}\right)\right]_{n}$; (B) Concentration-dependent emission spectra of probe in the presence of paraquat $\left(\lambda_{\mathrm{ex}}=340 \mathrm{~nm}\right)$; (C) Fitting curve for a nonlinear Stern-Volmer plot. Schematic illustration of the formation process of Ag@ZIF-8 nanowires and SERS detection.

More interestingly, one thins films $\mathrm{Cu}_{3}$ (BTC) @ @SiO,/BDC-PANI were synthesized by coating $\mathrm{Cu}_{3}(\mathrm{BTC})_{2} @ \mathrm{SiO}_{2}$ on organic ligand $\mathrm{H}_{3}$ BTC (98\%). These thin films were then utilized in the assembly of the conductometric sensing platform for detection of atrazine. This electrochemical immunosensor showed high sensitivity with a LOD as low as $0.01 \mathrm{nM}$ in aqueous solution [36].

\subsection{Detection of Heavy Metals}

\subsubsection{Mercury}

Because mercury is of extreme toxicity and high solubility in water, very low level of concentration of mercury ions in the ground water system will undeniably cause fatal and long-lasting risks to the human life and the environment $[53,54]$, considerate attention in relevant studies have been attracted to develop facile, instant and low-cost sensing approaches to detect and even remove this widespread heavy metal at very low concentrations. A Zn-based MOF formulated as $\left[\mathrm{Zn}(\mathrm{OBA})-(\mathrm{DPT})_{0.5}\right] \cdot \mathrm{DMF}$ (TMU-34(-2H)) was synthesized through the photoluminescence method by utilizing $4,4^{\prime}$-oxybis(benzoic acid) as the organic ligand and 3,6-di(pyridin4-yl)-1,2,4,5-tetrazine as the spacer. Its exceptionally sensitive and accurate detection (LOD in water: $1.8 \mu \mathrm{M}$; LOD in acetonitrile: $6.9 \mu \mathrm{M})$ within short response time (15 s) toward $\mathrm{Hg}^{2+}$ could be attributed to both the different signal transductions of the tetrazinefunctionalized motifs and the double solvent sensing method used [55]. A series of facile $\mathrm{Zn}$-based LMOFs, i.e. $\mathrm{Zn}_{2}$ (ofdc) (tppe) (LMOF-261), $\mathrm{Zn}_{2}$ (hfdc) ${ }_{2}\left(\right.$ tppe) (LMOF-262), $\mathrm{Zn}_{2}\left(\mathrm{dbtdcO}_{2}\right)_{2}$ (tppe) (LMOF-263) were established by Rudd et al. [56] to work as both sensor and adsorbent of $\mathrm{Hg}^{2+}$ from aqueous solutions (Figure 3A-3C).
The Powder X-ray diffraction (PXRD) pattern results confirm their similar isoreticular structures. The needle-shaped crystalline composite LMOF-263 was solvothermal synthesized by incorporating a tppe chromophore ligand and a sulfone-functionalized co-ligand dibenzo[b,d]thiophene-3,7-dicarboxylic acid 5,5-dioxide. Its intrinsic stability toward water and high fluorescence quantum yield (89.2\%) qualifies it as a desirable sensory material (Figure 3E). The LMOF-263 exhibited high sensitivity and selectivity toward $\mathrm{Hg}^{2+}$ with satisfactory quenching efficiency at very low concentration (3.3 ppb). Furthermore, it performed remarkably in selectively capturing and removing the $\mathrm{Hg}^{2+}$ from water within $30 \mathrm{~min}$. The sulfur and oxgen in the LMOF plays a key role in the interactions between $\mathrm{Hg}^{2+}$ and the sulfone moiety (Figure $3 \mathrm{~F}$ ). This sensing strategy provides a practical remediation alternative to solve environmental crisis. Another novel biosensing platform for detection for mercury ions was developed by using the combination of the MOF UiO-66- $\mathrm{NH}_{2}$ and a T-rich FAM-labeled ssDNA [57]. This hybrid system utilizing $\mathrm{T}-\mathrm{Hg}^{2+}-\mathrm{T}$ specific interactions for $\mathrm{Hg}^{2+}$ assay exhibited excellent sensing performance with a low LOD at $17.6 \mathrm{nM}$. In addition, due to the high affinity of mercury ions to nitrogen atoms, $4,4^{\prime}, 4^{\prime \prime}$-s-triazine-1,3,5-triyltri-p-aminobenzoic acid was also utilized as the organic ligand for the synthesis of terbium-based MOFs for sensitive luminescent sensing of mercury ions in aqueous solutions. Its detection limit was as low as $4.4 \mathrm{nM}$ in natural water [58].

\subsubsection{Iron}

Iron is a widespread heavy metal contaminant in water. Due to the hazards it may cause to human health, the recommended permit limit of $\mathrm{Fe}$ in drinking water is as low as $0.3 \mathrm{ppm}$ [59]. Several 
A

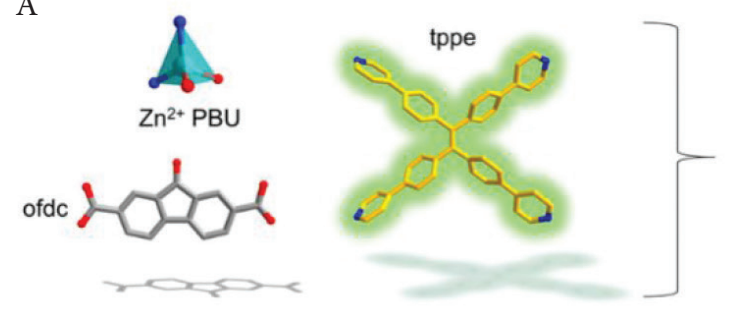

B

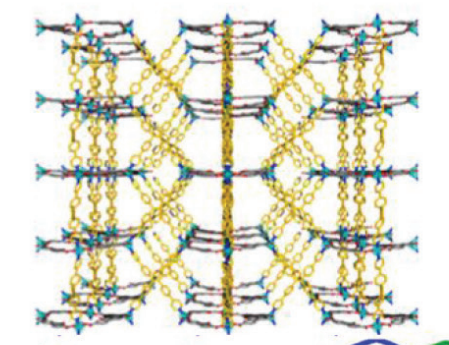

C

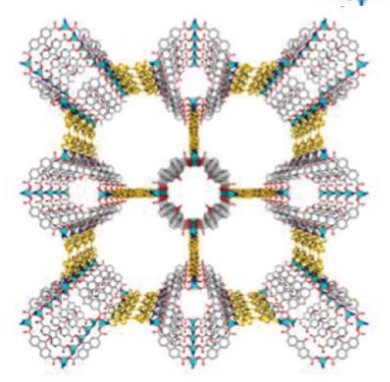

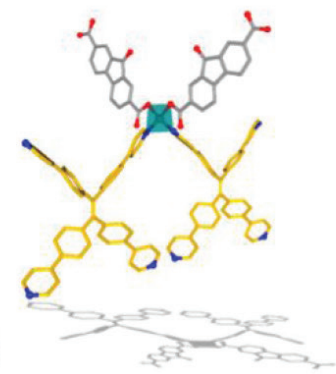

$\mathrm{E}$
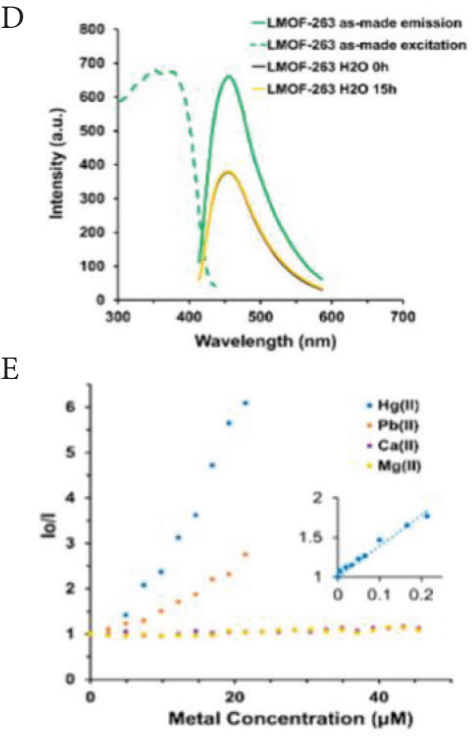

$\mathrm{F}$

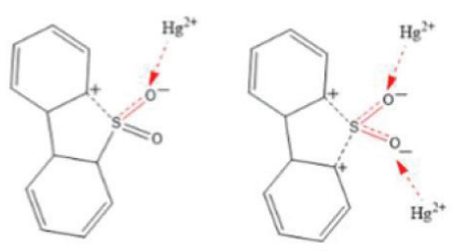

Figure 3 (A) The primary building unit of LMOF-261, depicting a pseudotetrahedrally coordinated Zn center bound to two tppe ligands and two ofdc linkers; (B) An individual net of the LMOF-261 framework viewed along the $b$-axis; (C) The same net depicted down the $c$-axis and simplified LMOF-261 depicting fourfold interpenetration; (D) LMOF-263 optical emission in the solid-state and as a suspension in water; $(\mathrm{E})$ Stern-Volmer curves $\left(\lambda_{\mathrm{ex}}=365 \mathrm{~nm}\right)$ for metal ions (inset, $\mathrm{Hg}^{2+}$ detection at low concentrations); (F) Interaction mechanism of $\mathrm{Hg}^{2+}$ with the sulfone functional group.

fluorescence-based MOFs have been constructed for the detection of $\mathrm{Fe}^{3+}$ ions by overcoming challenges caused by the low water stability of iron. A depleted uranium-based MOF, $\mathrm{UO}_{2}\left(\mathrm{C}_{8} \mathrm{H}_{3} \mathrm{O}_{6} \mathrm{~N}\right) \cdot \mathrm{DMF}$ was produced for the first time [60]. This compound was synthesized through solvothermal reactions to possess remarkable stability in aqueous media. This compound exhibits excellent selectivity toward iron ions (LOD $6.3 \mathrm{ppb}$ ) even with the interference of other ions. The luminescence quenching response of this composite was probably due to the competitive adsorption between $\mathrm{Fe}^{3+}$ and fluorescence probe. The nature of high selectivity and sensitivity of this sensory material made it promising for heavy metal detection. Two different water-stable Eu-MOF fluorescent sensors formulated as $\left[\left[\mathrm{Eu}_{2}(\mathrm{pdba})_{3}\left(\mathrm{H}_{2} \mathrm{O}\right)_{3}\right] \cdot 2 \mathrm{H}_{2} \mathrm{O}\right]_{n}(1)$ and $\left[\left[\mathrm{Eu}_{3}(\mathrm{pdba})_{4}\left(\mathrm{H}_{2} \mathrm{O}\right)_{4}\right] \cdot 5 \mathrm{H}_{2} \mathrm{O}\right]_{n}$ (2) were designed for detection of $\mathrm{Fe}^{3+}$ as well as $\mathrm{Cr}^{3+}$ in real environmental conditions [34]. The precursor compound terephthalic acid at different concentration was utilized in the synthesis of the sensing materials. To detect $\mathrm{Fe}^{3+}$ in aqueous solutions with powerful sensitivity and strong water stability, two Zr (IV)-based MOFs BUT-14 and BUT-15 were established with two similar ligands (i.e. $\mathrm{H}_{4} \mathrm{~L}^{1}$ and $\mathrm{H}_{4} \mathrm{~L}^{2}$ ) with minor difference in the functionalization. Between the two, BUT-15 demonstrated great repeatability and sensitivity (LOD $0.286 \mu \mathrm{M})$ with stable fluorescent quenching efficiency [61].

\subsubsection{Chromate}

The extensive chromate wastes have brought threats to the environment and subsequent hazards to human well-being [62]. MOFs have also been developed to detect the chromate anions in the natural water systems so as to purify water $[63,64]$. An Eu (III)-based luminescent $\mathrm{MOF}\left[\mathrm{Eu}_{7}(\mathrm{mtb})_{5}\left(\mathrm{H}_{2} \mathrm{O}\right)_{16}\right] \cdot \mathrm{NO}_{3} \cdot 8 \mathrm{DMA} \cdot 18 \mathrm{H}_{2} \mathrm{O}$ was constructed with a $3 \mathrm{D}$ structure for the detection of chromate anions in aqueous solutions [63]. Its outstanding sensing performance under real environments has been verified in the detection of chromate in deionized water, natural lake water and seawater. In the luminescence and analytical experiments, the detection limits reached as remarkably low as $0.56,2.88$ and $1.75 \mathrm{ppb}$ in the three different types of environmental water respectively (Figure 4$)$. A highly stable luminescent porous cationic framework $\left[\mathrm{Cd}(\mathrm{TIPA})_{2}\left(\mathrm{ClO}^{4-}\right)_{2}\right] \cdot(\mathrm{DMF}) 3\left(\mathrm{H}_{2} \mathrm{O}\right)$ was synthesized with a $2 \mathrm{D}$ layer. These structures were further constructed 3D structure through parallel packing, which exhibited high sensitivity and selectivity against $\mathrm{Cr}_{2} \mathrm{O}_{7}^{2-}$ in aqueous solutions. Remarkably, the detection limit was as low as 8 ppb [64].

\subsubsection{Other metal ions}

Similarly, $\mathrm{Cd}^{2+}, \mathrm{Pb}^{2+}, \mathrm{Co}^{2+}$ and other ions were also detected by using MOF based sensing techniques (Table 2) $[29,65,66]$. For instance, a highly sensitive conductive electrochemical sensor for detecting cadmium ions was constructed by coating the UiO66- $\mathrm{NH}_{2}$ with the conductive PANI polymer. The excellent analytical performance of the core-shell structure UiO-66- $\mathrm{NH}_{2} @ \mathrm{PANI}$ could be attributed to the chelation mechanism between $\mathrm{Cd}^{2+}$ and amine groups on the electrode. Even with the presence of other ions, this modified electrode still displayed high sensitivity toward 
A

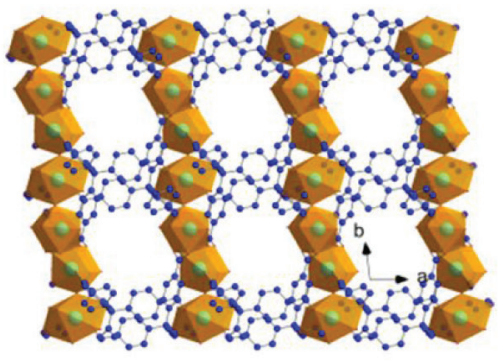

C

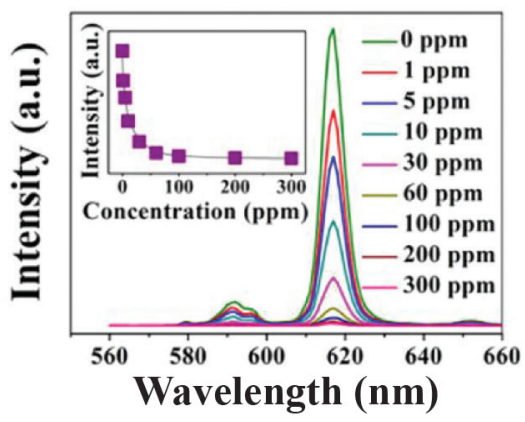

E

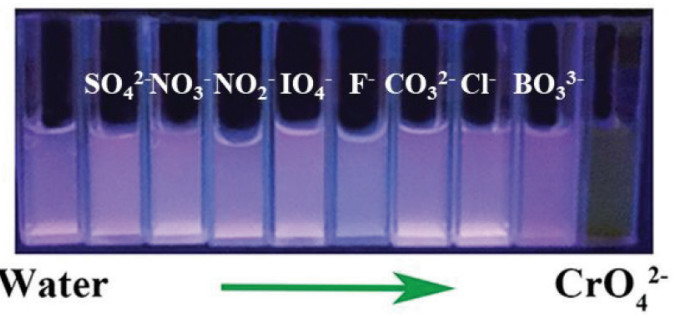

B

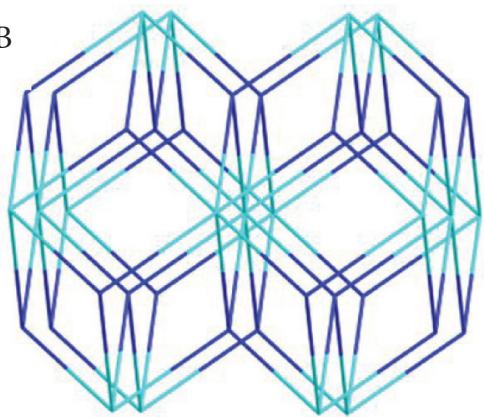

D

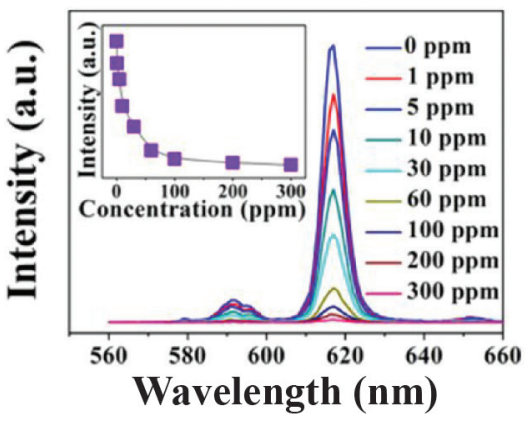

F

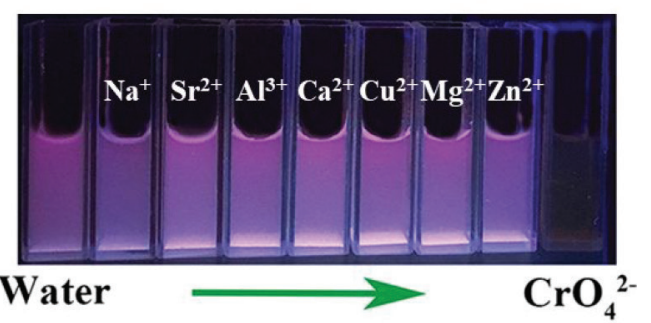

Figure 4 (A) Three-dimensional (3D) network structure viewed along the $c$-axis of Eu-MOF. (B) Its topological structure to show the (4,8)-connected 3D framework. PL spectra of Eu-MOF in Dushu Lake water (C) and seawater (D), respectively, with a wide range of chromium concentrations. Inset showing the quenching process. Corresponding luminescence photograph of Eu-MOF immersed in different anion

(E) or cation (F) solutions (excited at $365 \mathrm{~nm}$ ).

trace amount of $\mathrm{Cd}^{2+}$ ions with LOD as low as $0.3 \mu \mathrm{g} / \mathrm{L}$ with a wider linear range from 0.5 to $600 \mu \mathrm{g} / \mathrm{L}$ and higher stability. Moreover, $\left[\mathrm{Tb}(\mathrm{BPDC})_{2}\right] \cdot\left(\mathrm{CH}_{3}\right)_{2} \mathrm{NH}_{2}$ (DUT-101) as one kind of Tb-based MOFs with desirable stability in a $3 \mathrm{D}$ dual-channel structure was designed [35]. DUT-101 demonstrated high selectivity and sensitivity toward trace amount of $\mathrm{UO}_{2}^{2+}$ ions even in the mixture with different metal ions. The plausible sensing mechanism of this proposed strategy was the combination of the inhibition of fluorescence energy transfer and the improvement of electron molecular internal transition. Additionally, naked eye green fluorescent test papers were fabricated from this MOF, which could be used to detect $\mathrm{UO}_{2}^{2+}$ ions in drinking water with short response time.

\subsection{Detection of Other Contaminants}

There are many other contaminants that bring risks to food safety and human health, including environmental organic contaminants, mycotoxins among many others $[67,68]$. Here we selected a few representatives for a brief introduction (Table 3 ).

For mycotoxin detection, a rapid and selective sensing strategy at the ppb level was established by Hu et al. [69] (Figure 5). In the synthesis of this luminescent MOF, 1,1,2,2-tetrakis(4-(pyridin-4-yl)phenyl) ethane (tppe) and 4,4'-biphenyldicarboxylic acid were chosen to work as the ligands. The topological analysis of the LMOF-241 revealed its three-fold interpenetration without common symmetry operations (Figure 5D). $\mathrm{Zn}^{2+}$ ion selected ensured the strong ligand-based emission, which makes LMOF-241 an ideal sensory material. Probably owing to the electron transfer mechanism, this LMOF exhibits intense blue-green emission with desirable quantum yield at $92.7 \%$ (Figure 5F). And the tppe molecule as a strong fluorophore makes the selective emission quenching possible. With its intrinsic advantages of sensitivity and selectivity toward Aflatoxin $\mathrm{B}_{1}\left(\mathrm{AFB}_{1}\right)$, a detection method through luminescence quenching was developed with a detection limit as low as $46 \mathrm{ppb}$ for sensing $\mathrm{AFB}_{1}$ in aqueous solutions.

$\mathrm{Hu}$ et al. [70] also fabricated an easy and fast sensing material $\mathrm{Fe}_{3} \mathrm{O}_{4} / g-\mathrm{C}_{3} \mathrm{~N}_{4} /$ Hong Kong University of Science and Technology (HKUST-1) composite for OTA detection in corn sample. This as-synthesized polymer was obtained by linking $\mathrm{Fe}_{3} \mathrm{O}_{4}$ and $\mathrm{g}-\mathrm{C}_{3} \mathrm{~N}_{4}$ to the surface of HKUST-1 networks. HKUST-1 was selected to combine with the $2 \mathrm{D}$ structured $\mathrm{g}-\mathrm{C}_{3} \mathrm{~N}_{4}$ so as to inhibit the hydrophobicity and completely quench the fluorescence of the 5-carboxyfluorescein dye through photoinduced electron transfer. 
A
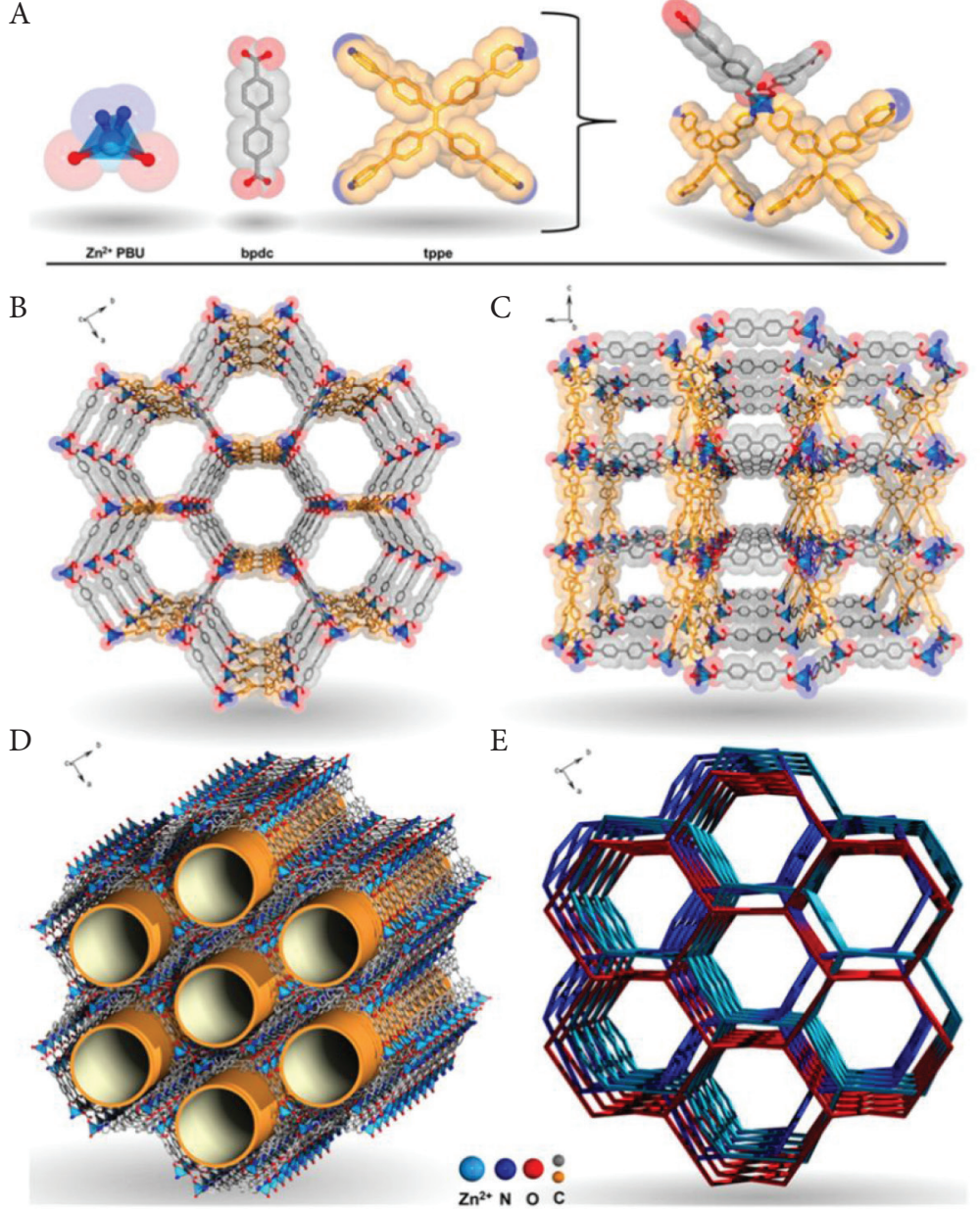

$\mathrm{F}$

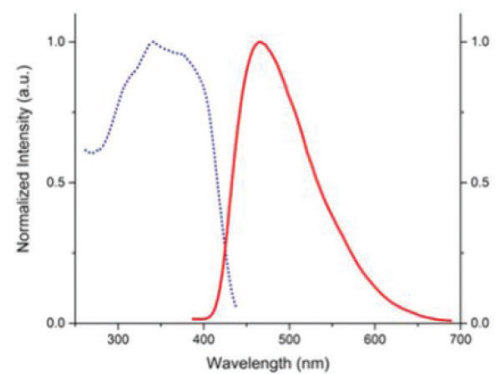

G

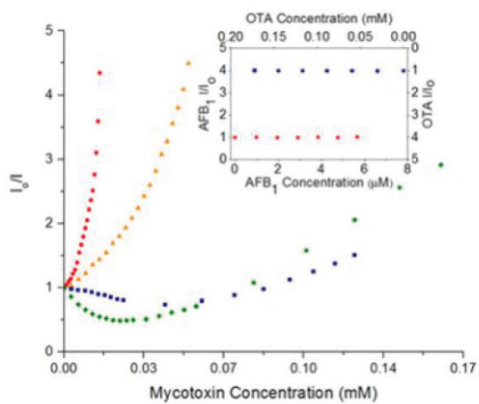

$\mathrm{H}$

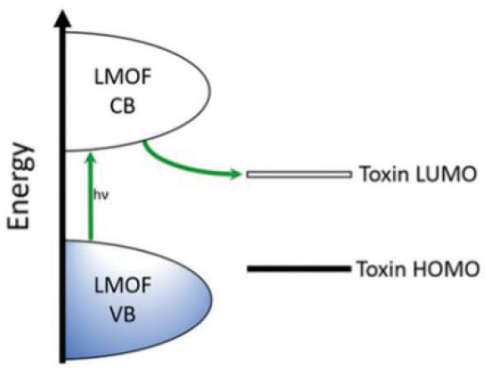

Figure 5 (A) Primary building unit of LMOF-241, showcasing a tetrahedrally coordinated Zn center bound to two tppe molecules and two bpdc molecules; (B) Single net of LMOF-241 framework viewed along the $c$-axis; (C) Single net of LMOF-241 framework viewed along the $b$-axis; (D) Overall crystal structure demonstrating the threefold interpenetration and 1D pore running along the $c$-axis; (E) LMOF-241 drawn as two-nodal (4,4)-c net (mog-type), with tppe and bpdc simplified as a 4-c node and 2-c node, respectively; (F) Excitation (dotted blue) and emission (solid red, $\lambda_{\text {ex }}=340 \mathrm{~nm}$ ) spectra of LMOF-241 suspended in dichloromethane; $(\mathrm{G})$ Stern-Volmer curves acquired at $\lambda_{\mathrm{ex}}=340 \mathrm{~nm}$ and $\lambda_{\mathrm{ex}}=410 \mathrm{~nm}$ (inset) for $\mathrm{AFB}_{1}$ (red dot), $\mathrm{AFB}_{2}$ (orange triangle), $\mathrm{AFG}_{1}$ (green diamond), and OTA (blue square); (H) Schematic demonstrating electron transfer from LMOF-241 to mycotoxin LUMO, resulting in quenched emission.

Subsequently, the excellent performance of this sensing platform toward OTA was owing to the fluorescence enhancement. The detection limit of this sensory strategy was found to be as low as $2.57 \mathrm{ng} / \mathrm{mL}$ in real corn samples.

Melamine is another very common contaminant of food owing to its high nitrogen content $[38,71,72]$. In a recent study, a functionalized electrochemiluminescence sensor for facile and rapid detection of melamine was prepared through stabilizing $\mathrm{Ru}(\mathrm{bpy})_{3}^{2+}$ in the bioMOF-1 framework $\left[\mathrm{Zn}_{8}(\mathrm{ad})_{4}(\mathrm{BPDC})_{6} \mathrm{O} \cdot 2 \mathrm{Me}_{2} \mathrm{NH}_{2}, 8 \mathrm{DMF}, 11 \mathrm{H}_{2} \mathrm{O}\right]$ [73]. This novel ECL sensor demonstrated high sensitivity toward melamine in a wide linear range $\left(10^{-10}-10^{-4} \mathrm{M}\right)$ with very low detection limit $(0.038 \mathrm{nM})$, which also showed good repeatability in the real sample of milk and instant formula power. Cai et al. prepared a core-shell nanoparticle Au@MIL-101 through polymerizing Materials of Institute Lavoisier (MIL-101) around AuNPs@IP for detecting methenamine particularly. This nanostructure demonstrated excellent SERS performance owing to great enhancement for Raman scattering. For its practical application in vermicelli samples, it showed very low LOD at $0.5 \mathrm{nM}$ with a great linear range between $3.16 \times 10^{-6}$ and $1.0 \times 10^{-8} \mathrm{M}[32]$.

\section{CONCLUSION}

In the current review, the recent technology advancements in MOFs-based sensor and their specific application in detection of pesticide residues, heavy metals and other toxic substances were summarized and reported.

The increasing demand of detecting health-or even life-threatening species in food, especially with great convenience and has been promoted by the enhanced awareness of assurance and improvement of food safety. MOFs with their intrinsic merits of modifiable pore structure, large surface area and "high density of active sites" have made them excellent candidates as the sensing materials for development of food contamination sensing platforms. In particular, the versatility of novel MOFs has been magnified by their combination with other functional materials with improved sensing performance. In general, the analytical methods for pesticide detection by using fluorescent MOF are developed based on the fluorescent quenching effect, which attributes to the energy transfer from composite to analyte or the competition between analyte and MOF of energy from light source. Electron transfer 
between MOF and analyte is the major detection mechanism of electrochemical-based method. Similarly, energy transfer often exists in the sensing strategies due to the strong interactions between heavy metal ions and the specific moiety or atom in the MOFs. Furthermore, recognition element modification and signal amplification also have been used for sensitive and selective detection based on MOF.

Even with these progresses achieved, MOF application has been expected to overcome a series of limitations mainly caused by their water instability so as to improve their sensitivity, selectivity and reproducibility in aqueous conditions. Firstly, the optimization and utilization of the functional advantages of MOFs could be maximized to a greater extent for the application in the food industry through better understanding of the functionalities of MOFs, especially focusing on the development of MOF-based rapid methods suitable for food matrix (e.g. diagnostic kit and strip). Secondly, with consideration of the high possibility of multiple contaminants co-existing in food, multifunctional MOF materials are expected to be designed. Thirdly, the specificity of the MOFs-based sensing platforms is expected to improve, since most of the current MOFs could hardly detect a specific analyte from a family of pesticides with similar structures. Molecular imprinting technique, recognition unit incorporation, surface modification and related technologies could be integrated with MOF to greatly enhance the specificity and sensitivity of the analytical methods for targeted food contaminants. Furthermore, deepened understanding of the toxicology of MOFs should be obtained in the future studies, especially for those applied in the analysis of food and products closely related to human well-being. Last but not the least, more MOF materials with multifunction of sensing, capturing and removing target analytes simultaneously in food are expected to be developed.

\section{CONFLICTS OF INTEREST}

The authors declare they have no conflicts of interest.

\section{AUTHORS' CONTRIBUTION}

YX contributed in investigation, design, review and writing. YP contributed in investigation. ZG contributed in methodology. $\mathrm{HH}, \mathrm{COLU}$ and YW contributed in conceptualization, supervision, editing and critical review.

\section{ACKNOWLEDGMENT}

This work was financially supported by University of Macau (MYRG2019-00025-ICMS).

\section{REFERENCES}

[1] Griffiths E, Dooley D, Graham M, Van Domselaar G, Brinkman FSL, Hsiao WWL. Context is everything: harmonization of critical food microbiology descriptors and metadata for improved food safety and surveillance. Front Microbiol 2017;8:1068.
[2] Bai W, Du M. A new open access forum in global food and health science. eFood 2020;1:1.

[3] Cheng S, Tu M, Liu H, Zhao G, Du M. Food-derived antithrombotic peptides: preparation, identification, and interactions with thrombin. Crit Rev Food Sci Nutr 2019;59:S81-S95.

[4] World Health Organization. WHO estimates of the global burden of foodborne diseases. Foodborne diseases burden epidemiology reference group 2007-2015. Geneva, Switzerland: WHO; 2015, p. 265. Available from: https://www.who.int/foodsafety/ publications/foodborne_disease/fergreport/en/.

[5] Aung MM, Chang YS. Traceability in a food supply chain: safety and quality perspectives. Food Control 2014;39:172-84.

[6] Lam HM, Remais J, Fung MC, Xu L, Sun SSM. Food supply and food safety issues in China. Lancet 2013;381:2044-53.

[7] Lu Y, Song S, Wang R, Liu Z, Meng J, Sweetman AJ, et al. Impacts of soil and water pollution on food safety and health risks in China. Environ Int 2015;77:5-15.

[8] Wang PL, Xie LH, Joseph EA, Li JR, Su XO, Zhou HC. Metalorganic frameworks for food safety. Chem Rev 2019;119: 10638-90.

[9] Zhang M, Zeiss MR, Geng S. Agricultural pesticide use and food safety: California's model. J Integr Agric 2015;14:2340-57.

[10] Wei J, Xue Y, Dong J, Wang S, Hu H, Gao H, et al. A new fluorescent technique for pesticide detection by using metal coordination polymer and nanozyme. Chin Med 2020;15:22.

[11] Dixon SJ, Stockwell BR. The role of iron and reactive oxygen species in cell death. Nat Chem Biol 2014;10:9-17.

[12] Zecca L, Youdim MBH, Riederer P, Connor JR, Crichton RR. Iron, brain ageing and neurodegenerative disorders. Nat Rev Neurosci 2004;5:863-73.

[13] Tao Y, Xie S, Xu F, Liu A, Wang Y, Chen D, et al. Ochratoxin A: toxicity, oxidative stress and metabolism. Food Chem Toxicol 2018;112:320-31.

[14] Lu Q, Qin JA, Fu YW, Luo JY, Lu JH, Logrieco AF, et al. Modified mycotoxins in foodstuffs, animal feed, and herbal medicine: a systematic review on global occurrence, transformation mechanism and analysis methods. TrAC Trends Anal Chem 2020;133:116088.

[15] Pierrard MA, Kestemont P, Delaive E, Dieu M, Raes M, Silvestre F. Malachite green toxicity assessed on Asian catfish primary cultures of peripheral blood mononuclear cells by a proteomic analysis. Aquat Toxicol 2012;114-115:142-52.

[16] Gopinathan R, Kanhere J, Banerjee J. Effect of malachite green toxicity on non target soil organisms. Chemosphere 2015;120:637-44.

[17] El-Sayed ESM, Yuan D. Waste to MOFs: sustainable linker, metal, and solvent sources for value-added MOF synthesis and applications. Green Chem 2020;22:4082-104.

[18] Stock N, Biswas S. Synthesis of metal-organic frameworks (MOFs): routes to various MOF topologies, morphologies, and composites. Chem Rev 2012;112:933-69.

[19] Fang X, Zong B, Mao S. Metal-organic framework-based sensors for environmental contaminant sensing. Nano-Micro Lett 2018;10:64

[20] Masiá A, Suarez-Varela MM, Llopis-Gonzalez A, Picó Y. Determination of pesticides and veterinary drug residues in food by liquid chromatography-mass spectrometry: a review. Anal Chim Acta 2016;936:40-61.

[21] Narenderan ST, Meyyanathan SN, Babu B. Review of pesticide residue analysis in fruits and vegetables. Pre-treatment, extraction and detection techniques. Food Res Int 2020;133:109141. 
[22] Teng Z, Jiang X, He F, Bai W. Qualitative and quantitative methods to evaluate anthocyanins. eFood 2020;1:339-46.

[23] Wagner M, Lin KYA, Oh WD, Lisak G. Metal-organic frameworks for pesticidal persistent organic pollutants detection and adsorption - a mini review. J Hazard Mater 2021;413:125325.

[24] Islamoglu T, Chen Z, Wasson MC, Buru CT, Kirlikovali KO, Afrin $\mathrm{U}$, et al. Metal-organic frameworks against toxic chemicals. Chem Rev 2020;120:8130-60.

[25] Chang Z, Yang DH, Xu J, Hu TL, Bu XH. Flexible metal-organic frameworks: recent advances and potential applications. Adv Mater 2015;27:5432-41.

[26] Raza W, Kukkar D, Saulat H, Raza N, Azam M, Mehmood A, et al. Metal-organic frameworks as an emerging tool for sensing various targets in aqueous and biological media. TrAC Trends Anal Chem 2019;120:115654.

[27] Bai Y, Dou Y, Xie LH, Rutledge W, Li JR, Zhou HC. Zr-based metal-organic frameworks: design, synthesis, structure, and applications. Chem Soc Rev 2016;45:2327-67.

[28] Hao JN, Yan B, A water-stable lanthanide-functionalized MOF as a highly selective and sensitive fluorescent probe for $\mathrm{Cd}^{2+}$. Chem Commun (Camb) 2015;51:7737-40.

[29] Wang Y, Wang L, Huang W, Zhang T, Hu X, Perman JA, et al. A metal-organic framework and conducting polymer based electrochemical sensor for high performance cadmium ion detection. J Mater Chem A 2017;5:8385-93.

[30] Lin X, Gao G, Zheng L, Chi Y, Chen G. Encapsulation of strongly fluorescent carbon quantum dots in metal-organic frameworks for enhancing chemical sensing. Anal Chem 2014;86:1223-8.

[31] Chen H, Fan P, Tu X, Min H, Yu X, Li X, et al. A bifunctional luminescent metal-organic framework for the sensing of paraquat and $\mathrm{Fe}^{3+}$ ions in water. Chem Asian J 2019;14:3611-19.

[32] Cai Y, Wu Y, Xuan T, Guo X, Wen Y, Yang H. Core-shell Au@ metal-organic frameworks for promoting Raman detection sensitivity of methenamine. ACS Appl Mater Interfaces 2018; 10:15412-17.

[33] Liao J, Wang D, Liu A, Hu Y, Li G. Controlled stepwisesynthesis of core-shell Au@MIL-100 (Fe) nanoparticles for sensitive surface-enhanced Raman scattering detection. Analyst 2015;140:8165-71.

[34] Li H, Han Y, Shao Z, Li N, Huang C, Hou H. Water-stable Eu-MOF fluorescent sensors for trivalent metal ions and nitrobenzene. Dalton Trans 2017;46:12201-8.

[35] Ye J, Bogale RF, Shi Y, Chen Y, Liu X, Zhang S, et al. A waterstable dual-channel luminescence sensor for $\mathrm{UO}_{2}^{2+}$ ions based on an anionic terbium(III) metal-organic framework. Chemistry 2017;23:7657-62.

[36] Bhardwaj SK, Bhardwaj N, Mohanta GC, Kumar P, Sharma $\mathrm{AL}$, Kim KH, et al. Immunosensing of atrazine with antibodyfunctionalized $\mathrm{Cu}-\mathrm{MOF}$ conducting thin films. ACS Appl Mater Interfaces 2015;7:26124-30.

[37] Fan L, Wang F, Zhao D, Sun X, Chen H, Wang H, et al. Two cadmium(II) coordination polymers as multi-functional luminescent sensors for the detection of $\mathrm{Cr}(\mathrm{VI})$ anions, dichloronitroaniline pesticide, and nitrofuran antibiotic in aqueous media. Spectrochim Acta A Mol Biomol Spectrosc 2020;239:118467.

[38] Zhu H, Kannan K. Occurrence of melamine and its derivatives in breast milk from the United States and its implications for exposure in infants. Environ Sci Technol 2019;53:7859-65.

[39] Bao J, Hou C, Chen M, Li J, Huo D, Yang M, et al. Plant esterasechitosan/gold nanoparticles-graphene nanosheet composite-based biosensor for the ultrasensitive detection of organophosphate pesticides. J Agric Food Chem 2015;63:10319-26.

[40] Wang A, Costello S, Cockburn M, Zhang X, Bronstein J, Ritz B. Parkinson's disease risk from ambient exposure to pesticides. Eur J Epidemiol 2011;26:547-55.

[41] Sun Y, Wei J, Zou J, Cheng Z, Huang Z, Gu L, et al. Electrochemical detection of methyl-paraoxon based on bifunctional nanozyme with catalytic activity and signal amplification effect. J Pharm Anal 2020 [in press].

[42] Vikrant K, Tsang DCW, Raza N, Giri BS, Kukkar D, Kim KH. Potential utility of metal-organic framework-based platform for sensing pesticides. ACS Appl Mater Interfaces 2018;10:8797-817.

[43] Sahoo M, Vishwakarma S, Panigrahi C, Kumar J. Nanotechnology: current applications and future scope in food. Food Front 2020:1-20.

[44] Patel H, Rawtani D, Agrawal YK. A newly emerging trend of chitosan-based sensing platform for the organophosphate pesticide detection using acetylcholinesterase- a review. Trends Food Sci Technol 2019;85:78-91.

[45] He K, Li Z, Wang L, Fu Y, Quan H, Li Y, et al. A water-stable luminescent metal-organic framework for rapid and visible sensing of organophosphorus pesticides. ACS Appl Mater Interfaces 2019;11:26250-60.

[46] Deep A, Bhardwaj SK, Paul AK, Kim KH, Kumar P. Surface assembly of nano-metal organic framework on amine functionalized indium tin oxide substrate for impedimetric sensing of parathion. Biosens Bioelectron 2015;65:226-31.

[47] Wei W, Wang J, Tian CB, Du SW, Wu KC. A highly hydrolytically stable lanthanide organic framework as a sensitive luminescent probe for DBP and chlorpyrifos detection. Analyst 2018;143:5481-6.

[48] Guo C, Jin Q, Wang Y, Ding B, Li Y, Huo J, et al. Developing a unique metal-organic framework- $\left\{\left[\mathrm{Cd}(\mathrm{abtz})_{2}(\mathrm{NCS})\right] \cdot\left(\mathrm{ClO}_{4}\right)\right\}_{n}$ (abtz $=1$-(4-aminobenzyl)-1,2,4-triazole $)$ as fluorescent probe for highly selective and sensitive detection of ascorbic acid in biological liquid. Sens Actuat B 2016;234:184-91.

[49] Tao CL, Chen B, Liu XG, Zhou LJ, Zhu XL, Cao J, et al. A highly luminescent entangled metal-organic framework based on pyridine-substituted tetraphenylethene for efficient pesticide detection. Chem Commun (Camb) 2017;53:9975-8.

[50] Feng DD, Zhao YD, Wang XQ, Fang DD, Tang J, Fan LM, et al. Two novel metal-organic frameworks based on pyridylimidazole-carboxyl multifunctional ligand: selective $\mathrm{CO}_{2}$ capture and multiresponsive luminescence sensor. Dalton Trans 2019;48:10892-900.

[51] Wang XQ, Feng DD, Tang J, Zhao YD, Li J, Yang J, et al. A water-stable zinc(II)-organic framework as a multiresponsive luminescent sensor for toxic heavy metal cations, oxyanions and organochlorine pesticides in aqueous solution. Dalton Trans 2019;48:16776-85.

[52] Li Q, Gong S, Zhang H, Huang F, Zhang L, Li S. Tailored necklace-like Ag@ZIF-8 core/shell heterostructure nanowires for high-performance plasmonic SERS detection. Chem Eng J 2019;371:26-33.

[53] Wen S, Zeng T, Liu L, Zhao K, Zhao Y, Liu X, et al. Highly sensitive and selective DNA-based detection of mercury(II) with $\alpha$-hemolysin nanopore. J Am Chem Soc 2011;133:18312-17.

[54] Xu XY, Yan B. Fabrication and application of a ratiometric and colorimetric fluorescent probe for $\mathrm{Hg}^{2+}$ based on dual-emissive metal-organic framework hybrids with carbon dots and $\mathrm{Eu}^{3+}$. J Mater Chem C 2016;4:1543-9. 
[55] Razavi SAA, Masoomi MY, Morsali A. Double solvent sensing method for improving sensitivity and accuracy of $\mathrm{Hg}$ (II) detection based on different signal transduction of a tetrazinefunctionalized pillared metal-organic framework. Inorg Chem 2017;56:9646-52.

[56] Rudd ND, Wang H, Fuentes-Fernandez EMA, Teat SJ, Chen F, Hall G, et al. Highly efficient luminescent metal-organic framework for the simultaneous detection and removal of heavy metals from water. ACS Appl Mater Interfaces 2016;8:30294-303.

[57] Wu LL, Wang Z, Zhao SN, Meng X, Song XZ, Feng J, et al. A metal-organic framework/DNA hybrid system as a novel fluorescent biosensor for mercury(II) ion detection. Chemistry 2016;22: 477-80.

[58] Xia T, Song T, Zhang G, Cui Y, Yang Y, Wang Z, et al. A terbium metal-organic framework for highly selective and sensitive luminescence sensing of $\mathrm{Hg}^{2+}$ ions in aqueous solution. Chemistry 2016;22:18429-34.

[59] Cotruvo JA. 2017 WHO guidelines for drinking water quality: first addendum to the fourth edition. J Am Water Works Assoc 2017;109:44-51.

[60] Liu W, Xie J, Zhang L, Silver MA, Wang S. A hydrolytically stable uranyl organic framework for highly sensitive and selective detection of $\mathrm{Fe}^{3+}$ in aqueous media. Dalton Trans 2018;47:649-53.

[61] Wang B, Yang Q, Guo C, Sun Y, Xie LH, Li JR. Stable Zr(IV)based metal-organic frameworks with predesigned functionalized ligands for highly selective detection of $\mathrm{Fe}(\mathrm{III})$ ions in water. ACS Appl Mater Interfaces 2017;9:10286-95.

[62] VonHandorf A, Sánchez-Martín FJ, Biesiada J, Zhang H, Zhang X, Medvedovic M, et al. Chromium disrupts chromatin organization and CTCF access to its cognate sites in promoters of differentially expressed genes. Epigenetics 2018;13:363-75.

[63] Liu W, Wang Y, Bai Z, Li Y, Wang Y, Chen L, et al. Hydrolytically stable luminescent cationic metal organic framework for highly sensitive and selective sensing of chromate anions in natural water systems. ACS Appl Mater Interfaces 2017;9:16448-57.

[64] Fu HR, Zhao Y, Zhou Z, Yang XG, Ma LF. Neutral ligand TIPAbased two 2D metal-organic frameworks: ultrahigh selectivity of $\mathrm{C}_{2} \mathrm{H}_{2} / \mathrm{CH}_{4}$ and efficient sensing and sorption of $\mathrm{Cr}(\mathrm{VI})$. Dalton Trans 2018;47:3725-32.

[65] Esrafili L, Firuzabadi FD, Morsali A, Hu ML. Reuse of predesigned dual-functional metal organic frameworks (DF-MOFs) after heavy metal removal. J Hazard Mater 2021;403:123696.

[66] Xu GR, An ZH, Xu K, Liu Q, Das R, Zhao HL. Metal organic framework (MOF)-based micro/nanoscaled materials for heavy metal ions removal: the cutting-edge study on designs, synthesis, and applications. Coord Chem Reviews 2021;427:213554.

[67] He L, Bai L, Shan L, Yu P, Zhang L, Dou X, et al. Variations in fungal microbiota and aflatoxin contamination during the pro- cessing of Yuanzhi, a traditional Chinese medicine. Ind Crops Prod 2020;152:112509.

[68] Yu J, Guo M, Jiang W, Yang M, Pang X. Assessment of the microbiome and potential aflatoxin associated with the medicinal herb Platycladus orientalis. Front Microbiol 2020;11:582679.

[69] Hu Z, Lustig WP, Zhang J, Zheng C, Wang H, Teat SJ, et al. Effective detection of mycotoxins by a highly luminescent metalorganic framework. J Am Chem Soc 2015;137:16209-15.

[70] Hu S, Ouyang W, Guo L, Lin Z, Jiang X, Qiu B, et al. Facile synthesis of $\mathrm{Fe}_{3} \mathrm{O}_{4} / \mathrm{g}-\mathrm{C}_{3} \mathrm{~N}_{4} / \mathrm{HKUST}-1$ composites as a novel biosensor platform for ochratoxin A. Biosens Bioelectron 2017;92:718-23.

[71] Shi X, Dong R, Chen J, Yuan Y, Long Q, Guo J, et al. An assessment of melamine exposure in Shanghai adults and its association with food consumption. Environ Int 2020;135:105363.

[72] Li Q, Song P, Wen J. Melamine and food safety: a 10-year review. Curr Opin Food Sci 2019;30:79-84.

[73] Feng D, Wu Y, Tan X, Chen Q, Yan J, Liu M, et al. Sensitive detection of melamine by an electrochemiluminescence sensor based on tris(bipyridine)ruthenium(II)-functionalized metal-organic frameworks. Sens Actuat B 2018;265:378-86.

[74] Xu X, Guo Y, Wang X, Li W, Qi P, Wang Z, et al. Sensitive detection of pesticides by a highly luminescent metal-organic framework. Sens Actuat B 2018;260:339-45.

[75] Lai H, Shang W, Yun Y, Chen D, Wu L, Xu F. Uniform arrangement of gold nanoparticles on magnetic core particles with a metal-organic framework shell as a substrate for sensitive and reproducible SERS based assays: application to the quantitation of Malachite Green and thiram. Microchim Acta 2019;186:144.

[76] Cao X, Hong S, Jiang Z, She Y, Wang S, Zhang C, et al. SERSactive metal-organic frameworks with embedded gold nanoparticles. Analyst 2017;142:2640-7.

[77] Dalapati R, Kökçam-Demir Ü, Janiak C, Biswas S. The effect of functional groups in the aqueous-phase selective sensing of $\mathrm{Fe}(\mathrm{III})$ ions by thienothiophene-based zirconium metal-organic frameworks and the design of molecular logic gates. Dalton Trans 2018;47:1159-70.

[78] Wang X, Yang C, Zhu S, Yan M, Ge S, Yu J. 3D origami electrochemical device for sensitive $\mathrm{Pb}^{2+}$ testing based on DNA functionalized iron-porphyrinic metal-organic framework. Biosens Bioelectron 2017;87:108-15.

[79] Gao X, Zhao H, Zhao X, Li Z, Gao Z, Wang Y, et al. Aqueous phase sensing of bismuth ion using fluorescent metal-organic framework. Sens Actuat B 2018;266:323-8.

[80] Xing K, Fan R, Wang J, Zhang S, Feng K, Du X, et al. Highly stable and regenerative metal-organic framework designed by multiwalled divider installation strategy for detection of $\mathrm{Co}$ (II) ions and organic aromatics in water. ACS Appl Mater Interfaces 2017;9:19881-93. 